\title{
26362 - HEMODYNAMIC INSTABILITY FOLLOWING STAGED BILATERAL CAROTID ENDARTERECTOMY
}

\section{Vidya Chidambaran MD, Ramasamy Govindarajan, MD; Biswajit Ghosh, MD; Maged Seif, Lucio Flores, MD, FACP; Brookdale University Hospital And Medical Center, Brooklyn, NY, USA}

INTRODUCTION: Blood pressure (BP) and heart rate (HR) instability following carotid endarterectomy (CEA) have been extensively documented in the literature [1,2]. CEA has been associated with disturbance of the baroreceptor control mechanism caused by surgery in the carotid sinus region [1]. Smit and colleagues reported bilateral carotid sinus denervation producing long-term blood pressure variability [3]. In our study, we report finding profound hemodynamic instability during the 24-hour period following CEA on ten patients who had undergone a previous contralateral CEA (Group 1) and compare management of these patients with ten controls who underwent CEA without previous contralateral CEA surgery (Group 2).

METHODS: All patients underwent general endotracheal anesthesia with the same induction and maintenance regimen. BP and HR were recorded continuously perioperatively and for 24 hours postoperatively. Incidence of postoperative HTN , hypotension, bradycardia, maximal increase in HR and the associated use of corrective medications were recorded.

RESULTS: The incidence of refractory hypotension and bradycardia was higher in the bilateral CEA group (Group 1, n=7/10), while in the unilateral CEA group (Group 2), hypotensive and bradycardic response was transient and readily reversible. All patients exhibiting refractory hemodynamic instability in Group 1 required aggressive management with sympathomimetic and parasympatholytic medications for a period of 24-36 hours postprocedure in the PACU and SICU. Hypertension was a prominent feature in six patients in Group $2(n=6 / 10)$ while one patient in Group 2 developed cardiac dysrhythmia that required cardioversion. Only one patient in both groups needed hospitalization longer than 72 hours on account of recurrent cardiac dysrhthmia.

DISCUSSION: Not withstanding the small sample size, our results indicate that bilateral CEA is associated with significant hemodynamic instability and often requires aggressive pharmacotherapy. Awareness, early diagnosis and prompt treatment improve outcome and often single out patients who need closer follow-up during the posthospitalization period. Our data showed that hemodynamic instability does not significantly affect early discharge [4] and routine intraoperative injection of bupivacaine at the carotid sinus level does not reduce the level of postoperative hypotension.

REFERENCES:

1. J Vasc Surg 2002, 36:793-798.

2. Stroke 1996, 27:1167-1172.

3. Circulation 2002, 19:1329-1335.

4. Cardiovacs Surg 1998, 6:470-474. 


\begin{tabular}{|c|c|c|c|c|c|c|c|c|c|c|}
\hline $\begin{array}{l}\text { VARLABLE } \\
\text { (MEAN } \\
\text { VALUES) }\end{array}$ & \multicolumn{2}{|c|}{$\begin{array}{c}\text { SYSTOLIC } \\
\text { BLOOD } \\
\text { PRESSURE }\end{array}$} & \multicolumn{2}{|c|}{$\begin{array}{l}\text { DLASTOLIC } \\
\text { BLOOD } \\
\text { PRESSURE }\end{array}$} & \multicolumn{2}{|c|}{$\begin{array}{l}\text { HEART } \\
\text { RATE }\end{array}$} & \multicolumn{2}{|c|}{$\begin{array}{l}\text { \%STENOSIS } \\
\text { OPERATED } \\
\text { SDE }\end{array}$} & \multicolumn{2}{|c|}{$\begin{array}{l}\text { \%STENOSIS } \\
\text { CONTRA. } \\
\text { LATERAL }\end{array}$} \\
\hline Turing & \begin{tabular}{|l|} 
Groatpl \\
\end{tabular} & Group2 & Groupl & Groesp2 & Grocapl & Grotg?2 & Group! & Groug/2 & Groupl & Group \\
\hline Preopsrative & $140 \pm 12$ & $160 \pm 9$ & $79 \pm 6$ & $88 \pm 3$ & $65 \pm 6$ & $72 \pm 6$ & $79 \pm 11$ & $82 \pm 9$ & $5 \pm 9$ & $55=8$ \\
\hline $\begin{array}{l}\text { Imanediate } \\
\text { postoperative }\end{array}$ & $86 \pm 5$ & $210 \pm 11$ & $38 \pm 6$ & $95 \pm 6$ & $47 \pm 8$ & $93 \pm 7$ & . & . & . & . \\
\hline $\begin{array}{l}2 \text { dyys } \\
\text { postoperative }\end{array}$ & $109 \pm 9$ & $170 \pm 9$ & $60 \pm 6$ & $82 \pm 7$ & $58 \pm 3$ & $76 \pm 5$ & - &. & - & . \\
\hline $\begin{array}{l}1 \text { year } \\
\text { postoperative }\end{array}$ & $128 \pm 6$ & $155 \pm 8$ & $78 \pm 7$ & $80 \pm 6$ & $62 \pm 3$ & $70 \pm 4$ & $5 \pm 6$ & $8 \pm 3$ & $8 \pm 12$ & $58 \div 9$ \\
\hline
\end{tabular}

